\title{
Detector Requirements to Curb Nuclear Smuggling
}

\author{
S.A. Erickson
}

This article was submitted to IEEE Conference 2001, Nuclear Science Symposium, San Diego, CA, November 6-10, 2001

\section{November 14, 2001}

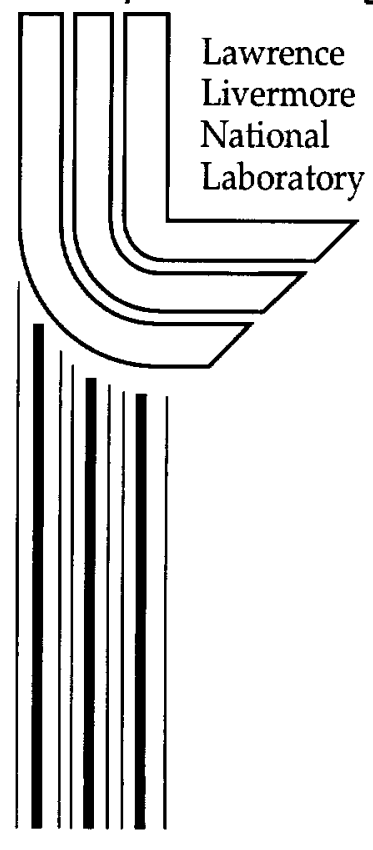




\section{DISCLAIMER}

This document was prepared as an account of work sponsored by an agency of the United States Government. Neither the United States Government nor the University of California nor any of their employees, makes any warranty, express or implied, or assumes any legal liability or responsibility for the accuracy, completeness, or usefulness of any information, apparatus, product, or process disclosed, or represents that its use would not infringe privately owned rights. Reference herein to any specific commercial product, process, or service by trade name, trademark, manufacturer, or otherwise, does not necessarily constitute or imply its endorsement, recommendation, or favoring by the United States Government or the University of California. The views and opinions of authors expressed herein do not necessarily state or reflect those of the United States Government or the University of California, and shall not be used for advertising or product endorsement purposes.

This is a preprint of a paper intended for publication in a journal or proceedings. Since changes may be made before publication, this preprint is made available with the understanding that it will not be cited or reproduced without the permission of the author.

This work was performed under the auspices of the United States Department of Energy by the University of California, Lawrence Livermore National Laboratory under contract No. W-7405-Eng-48.

This report has been reproduced directly from the best available copy.

Available electronically at http://www.doc.gov/bridge

Available for a processing fee to U.S. Department of Energy

And its contractors in paper from

U.S. Department of Energy

Office of Scientific and Technical Information

P.O. Box 62

Oak Ridge, TN 37831-0062

Telephone: (865) 576-8401

Facsimile: (865) 576-5728

E-mail: reports@adonis.osti.gov

Available for the sale to the public from

U.S. Department of Commerce

National Technical Information Service

5285 Port Royal Road

Springfield, VA 22161

Telephone: (800) 553-6847

Facsimile: (703) 605-6900

E-mail: orders@ntis.fedworld.gov

Online ordering: http://www.ntis.gov/ordering.htm

OR

Lawrence Livermore National Laboratory

Technical Information Department's Digital Library

http://www.llnl.gov/tid/Library.html 


\title{
Detector Requirements to Curb Nuclear Smuggling
}

\author{
Stanley A. Erickson
}

\begin{abstract}
The problem of stopping nuclear smuggling of terrorist nuclear devices is a complex one, owing to the variety of pathways by which such a device can be transported. To fashion new detection systems that improve the chances of detecting such a device, it is important to know the various requirements and conditions that would be imposed on them by both the types of devices that might be smuggled and by the requirement that it not overly interfere with the transportation of legitimate goods. Requirements vary greatly from lowvolume border crossings to high-volume industrial container ports, and the design of systems for them is likely to be quite different. There is also a further need to detect these devices if they are brought into a country via illicit routes, i.e., those which do not pass through customs posts, but travel overland though open space or to a smaller, unguarded airport or seaport. This paper describes some generic uses of detectors, how they need to be integrated into customs or other law enforcement systems, and what the specifications for such detectors might be.
\end{abstract}

\section{INTRODUCTION}

The problem of smuggling of fissile and radioactive 1 materials is a worldwide one. Fissile materials are usable in covert nuclear proliferation problems, leading to an expansion of the number of nuclear powers, with all the attendant dangers. They are also attractive materials for terrorists, including weapons themselves and the fissile materials that can be used to make them. Nuclear smuggling of weapons can also be used for military purposes by a country lacking delivery capability or seeking to remain covert[1].

Radioactive materials create problems of their own. They can also be used for terrorist purposes, in a radioactivity dispersal device (RDD), designed to cause panic. Radioactive sources can be shipped inadvertently or deliberately not marked as such, leading to a health hazard. Because nations may impose import or export duties on such sources, enterprises may see to avoid such duties by failing to

Manuscript received November 14, 2001. This work was performed under the auspices of the U.S. Department of Energy by University of California, Lawrence Livermore National Laboratory under contract No. W-7405-Eng-48.

S. A. Erickson is with the Lawrence Livermore National Laboratory, University of California, Livermore, CA 94550 USA (telephone: 925-4226548, e-mail: serickson@llnl.gov). declare the items on their shipping declarations. Also, these sources may be lost, through the bankruptcy of a holder of them, careless handling or other ways. Once lost, they may be shipped by people who do not understand they are, which can lead to health hazards as well. These sources can be accidentally mixed in with scrap metal, leading to contaminated reclaimed metal. Contamination can also occur from other sources, such as the fallout from Chernobyl. The problem of radioactive contamination has risen to the point where large conferences are devoted to the subject, e.g., the recent IAEA conference in May, 2001, entitled "On the Protection of Radioactive and Nuclear Materials".

Nations may be faced with any or all of these problems, and may assign priorities as they see fit. The detector requirements for these four problem areas: nuclear proliferation, nuclear terrorism, radioactive sources, and radioactive materials, are different, and compromises sometimes need to be made to meet two or more of the goals. International cooperation programs may, for example, find a nation interested in counter-terrorism or non-proliferation providing assistance to one that considers illicit shipping of nuclear waste across its borders of prime importance. This means that the detector requirements must meet both goals.

The smuggling of fissile materials for proliferation purposes or for terrorism is a matter of increasing concern. It is of concern for countries that may be sources of the materials, for countries across which they transit, and especially for those countries that might be targets for terrorist activity. Developing detectors that improve the chances that such material will be discovered and interdicted would be of great benefit, and reducing the cost of these devices, of their installation, and of their maintenance would also help in allowing more of them to be used in more countries and locations.

\section{BASIC REQUIREMENTS FOR ILLICIT ROUTES}

To combat nuclear smuggling, it is useful to understand the dimensions of the problem before considering how to defeat it. The routes and methods smugglers can use are legion. Smuggling can occur by illicit routes, traveling over land borders, across riverine borders, or from a noninternational port or shoreline anywhere, or from a non- 
international airport. It can also occur at a Customs location marking a legal international border crossing.

\section{A. Illicit route requirements}

Stopping smuggling via illicit routes is typically done by border patrols. This would be land patrols for land crossings and crossings of rivers that are not navigable, by patrol craft on navigable rivers, by coastal patrol on shorelines and outside non-international ports, and by radar search followed by air interception for aircraft proceeding to or from noninternational airports or using ad hoc landing strips. Improvements in the ability to stop nuclear smuggling can be done by enhancing these search and interdiction capabilities. However, since nuclear materials, unlike almost all other materials, produce radiation that is detectable by remote instruments, it might be possible to detect an illicit nuclear cargo if an appropriate location could be found. Nuclear smugglers choosing to cross the border via an illicit route may not travel through their entire route avoiding roads or other legitimate internal routes. It is likely that they would travel the majority of their planned route using an ordinary road. For example, smugglers intending to exit a country via an informal landing strip or via a small fishing port would likely drive by ordinary roads to these debarkation spots. If locations could be found along their route where nuclear radiation monitors could detect their passage with enough speed so that law enforcement response forces could intercept them, then their choice of illicit route would be for naught.

A number of locations might be designated as worth monitoring, based on known smuggling traffic or their position between expected origin locations or origin national borders and expected destinations or destination nations. These sites would have to be numerous enough so that they would be passed by a large majority of traffic moving from an expected origin to an expected destination.

The sensitivity requirements for such monitors are inversely proportional to the speed of the traffic passing by. This means that only locations where the traffic slowed to a crawl or stopped are preferable. Such locations might be exit and entry points to major roads, such as freeways or highways, smaller traffic circles, stoplights and other traffic stopping locations, isolated gas/service stations on less-traveled roads, toll booths, truck weighing stations, or narrow bridges. Because of the number of such locations, the monitors would have to be relatively inexpensive. However, there are a number of other conditions that need to be imposed on such monitors. First, it would be unlikely that personnel could be found to stand by the monitor for any reason. Thus, they need to be inconspicuous to reduce theft and sabotage. They need to work autonomously. They need to be able to report rapidly any detection of a likely smuggling attempt and to provide enough information so that the vehicle creating the detection alarm could be identified.

\section{B. Response-generated requirements}

These alarms would be responded to by agents of a law enforcement agency, for example, the police, local militia, or Customs agents. It is imperative that there be a means for reducing false alarms, as the responding agency cannot keep sending agents out to intercept vehicles for no benefit. This reduction of false alarms can be done at the monitor itself, if it has some ability to discriminate the radiation it receives, or to intercept other signatures of the vehicle. Being able to recognize the signature of a particular type of ore truck might be adequate to eliminate false alarms from ore mined nearby that had some uranium content. Time of passage, vehicle dimensions or other aspects, or spectroscopic information might serve this purpose. Alternately, the monitor could forward such signature data to the responding agency if they had the ability to discriminate against false alarms. This is clearly a tradeoff between communications and computing.

The monitors would also have to operate for long periods unattended. This means that they would either have to be connected to available public power, for example from a city lamppost upon which the monitor was mounted, or to have very long life batteries and low power consumption. They would also have to be self-calibrating in the face of environmental changes, including day and might, winter and summer, rain or snow or dry, and various changes of background from atmospheric radon, blowing dust, or other site-specific background sources.

\section{BASIC REQUIREMENTS FOR LEGAL ROUTES}

Customs posts for land, rail, and pedestrian crossing allow a fairly simple means of radiation detection. Portal monitors exist that can detect large enough quantities of fissile and radioactive materials. These monitors should be made less expensive and more sensitive with improved technology, so that more of them could be emplaced at border crossings. The detection of shielded highly-enriched uranium continues to be a difficult challenge.

At the borders, truck traffic typically passes through multilane customs checkpoints, and so detectors for this mode of entry should be able to operate effectively in this environment. Rail traffic can be monitored either while enroute across the border, or at a customs checkpoint inside the nation. Airports and seaports, however, pose unique problems, as do some rail facilities. In countries using modern systems of cargo delivery, the passing of a customs border at a rail terminal, seaport, or airport, does not mean that any customs official has contact with it. For selected shippers, and this is the large majority in countries with high traffic volumes, containers can be shipped to a customs location near the destination location, rather than obtaining customs authorization at their port of entry. This has implications for the detection systems, as if they are located at port of entry, some means of designating and interdicting the cargo needs to be part of the detector system concept. If 
located at the customs warehouses where the cargo is packed and sealed, larger numbers would be required, and security considerations would have to be met.

\section{A. Airport requirements}

Airports can also be dealt with using portal monitors as well. The locations of the monitors need to be determined on an individual airport basis using a system architecture study. This type of study analyzes the amount and type of traffic at an international airport. Typically there are passenger flows, employee flows, air cargo flows, mail flows, small aircraft flows, and diplomatic flows. Each of these has to be funneled through an adequate set of monitors. In some cases this does not require a rerouting of the traffic flow, as the monitors can be set alongside existing traffic routes when they pass through chokepoints, such as immigration checkpoints, customs checkpoints, area gates, warehouse entryways, conveyor belts, and other types of traffic moving devices

An airport is typically well-sealed along its borders and wellcontrolled in its traffic, because of the persistent threat of hijackers, drug smugglers, or other criminal elements. If an airport has been successful in developing procedures and protection means that prevent drug smuggling, it will also have prevented nuclear smuggling except by legitimate routes. Thus, a secure airport needs to be equipped with radiation detection equipment along all legitimate routes of entry and exit to make it completely sealed.

\section{B. Seaport requirements}

Seaports are typically far less controlled than airports, as there is no hijacking threat. There is a drug smuggling threat, and seaports continue to provide interception opportunities for the Customs Service and drug enforcement agencies. In order to seal a seaport to the level that an airport is typically sealed, the same level of attention and expense must be paid to external fences, monitors, employee control, vehicle control, and sensors of various types. If this is done, the same problem then is faced in monitoring the legitimate traffic routes into and out of the port for nuclear radiation.

To provide some more details about the needs here, consider a particular dock at an international shipping port, and that the dock is devoted to container shipping. A large container ship may contain up to 8000 containers, and these will be unloaded in a day and a half. Thus there is a continuous rapid flux of containers out of the dock area, and any detector system must be capable of coping with the flow rate, as traffic cannot be backed up for long without crimping the balance sheet of the company owning the ships and the dock. There may be little spare space available to mount a large number of detector stations, so some other solution might be profitably sought. Furthermore, detecting nuclear material in a container is a difficult challenge. Available options include passive gamma and neutron detectors, scanning internally with such detectors - possibly hand-held or portable, active neutron screening, low technology measurements of weight and moment and comparison with the shipping manifest and typical containers manifested identically, X-ray or particle scanning, or, in the final stage, physically searching the contents. The difficulty that arises from the large volume of the container is that shielding may be applied all around nuclear material that is being shipped, for example, for a terrorist device. This eliminates the possibility of passive detection, but it enhances the opportunity for various types of scanning and screening. Hopefully, a complete suite of detection apparatus would cover all combinations of nuclear material mass and shielding mass.

Nuclear detectors might be mounted on the unloading equipment or right next to it, in order to process containers rapidly and to provide an alarm in enough time that the container can be routed to a search area for more intensive investigation. However, such a location is fraught with environmental conditions, such as vibration and shock, sea moisture, temperature changes, noise and various pollutants. It is about as far from ideal laboratory conditions as it is possible to conceive. However, given that some loss of sensitivity might be necessary and tolerable compared to benign environments, detectors might be developed for this purpose.

\section{ASSESSMENT}

It is also necessary to perform assessment of the discovered material promptly in a law enforcement situation. Especially in the situation where a terrorist device has been discovered, it would be very useful to characterize it as soon as possible, so that other devices of similar design might be specially sought for along other borders. This also has implications for necessary equipment, as well as for specialized training for those officials who will use it. While it would be possible to remove the device to a remote location to investigate it, the time involved might cause lost opportunities. Other situations, such as revenue evasion, can be dealt with more leisurely, and if the detector suite is able to assess what the situation is, it can be dealt with as quickly as necessary, but without the costs of immediate and substantial response. It must be remembered that a terrorist attack is extremely unlikely at any post, but revenue evasion is just the opposite. Filtering out one from another is an important requirement.

For other situations, such as high volume container ports, different arrangements must be made, and the design of the detection system needs to be such so that as few as possible of these legitimate sources of radioactivity are mixed into the traffic that needs to be evaluated at a secondary screening location for terrorist devices. This can be done by spectroscopic evaluation or by the use of shipping manifest data that indicate legitimate radioactive source shipment. Flynn[2] gives an indication of how such a system might be integrated into existing the import traffic system in the United States. 


\section{ATTRIBUTION}

The last task that detection and identification equipment can be called on to do is attribution. This means providing law enforcement agencies with as much information as possible so that those ultimately responsible for the violation can be dealt with appropriately. This may be done by spectroscopic means in certain situations, but more often forensic techniques have to be added. If the detection suite can provide preliminary information, it would be of assistance while the more elaborate laboratory analysis is being done.

\section{CONCLUSIONS}

In summary, there are many interesting challenges for the detection of fissile and radioactive materials as part of a counter-smuggling program. Each country that desires such protection and enforcement activity will specify its target materials and this, in conjunction with a good detailed understanding of the traffic flows within the country, will serve to provide quantitative requirements for detector suites. Obviously, quantitative specifications must remain unpublicized, as such information could be used by smugglers to enhance their ability to escape detection. However, commercial as well as government organizations could provide very sorely needed by contributing as possible to the improvement of instruments and apparatus for the solution of this problem.

\section{REFERENCES}

[1] Erickson, Stanley A., "Nuclear Weapon Prepositioning as a Threat Strategy", Journal of Homeland Security, July 2001, http://www.homelandsecurity.org/journal/Articles/article.cfm?article=15.

[2] Flynn, Stephen E., "Beyond Border Control", Foreign Affairs, vol. 79, no. 6, pp 57-68, November/December 2000. 